\title{
ERRORS AND MISTAKES FOUND IN NON- ENGLISH STUDY PROGRAMSTUDENTS WRITING PRODUCTS
}

\author{
Sijono, Ilinawati \\ STKIP Persada Khatulistiwa Sintang \\ Sijonostg4@gmail.com,selvinilina@gmail.com
}

Submitted: 2020-10-03

Accepted : 2020-11-16

\begin{abstract}
This study focuses on students' errors that occur when asked to write simple present tense to non-English English study program students at a private university in the border area of West Kalimantan. Researchers conducted this research to get an overview of the causes of students making mistakes and errors in writing simple present tense.In analyzing the data, the researchers used qualitative research design to describe the various forms of errors or mistakes students when writing simple present tense. The data analysis in this study was taken from 120 Non-English Study program students. The researchers applied purposive sampling to determine the research subject.Based on the number of sampling of the research, the researchers analyzed 120 worksheets of the students translation task.Researchers found a total of 395 cases. The findings showed that all cases described in this study were categorized as errors. The researchers found that students failed to carry out their knowledge of the simple present tense. The most common errors found in this study, such as the rule of adding extra 's / es', the rule of using 'Tobe' and errors arising from the addition of 'Ving' can be minimized with regular writing practice.
\end{abstract}

Keywords : Errors, Mistakes, Students writing Products

\section{INTRODUCTION}

Writing is a complex activity in English subject which take complex process during the activity. Writing is a process of expressing ideas through letters, phrases and sentences. When writing a student needs to consider what kind of tenses is going to be used to express thier ideas. Grammartical rules make many students think that english is a complicated subject. A lot of students from variousbackground of mother tongues learn English as a second or third language. In Indonesia students learn English as a foreignlanguage in all level. They learn the language as a compulsorysubject at school or at a university. Students make both errors and mistakes when writing english sentences, especially for students of non-English study program.Both errors and mistkesarrise from the students' understanding of the grammartical rules of the target language. Indoesian students make both errors and mistakes because the grammar of English and Indonesia is different (Leacock, Chodorow, Gamon, \&Tetreault, 2010).

Writing in English is a complicated activities which take complex process more over for Non- English study program students. That is why, It is no wonder both errors and mistakes in students' writing products are unavoidable to be found.In analzying both errors and mistakes made by the students, Corder recommended several ways.Corder in (Ellis, 1994) states that errors occur when deviations arise as a result of a lack of knowledge which is a lack of competence in performing the knowledge. While, He stated that errorhappens when the students fail to perform their knowledge of the grammar. It could happen because some problems might prevent students to access their knowledge of the target language they have experienced. That's 
why studentsmay return to alternative of a non-standard rules that they have easier access to. Mistakes happens because of a performance phenomena. A mistake is something natural, where the students break the rule of the grammartical .This could be the result of the teacher's process of identification, correction and even neglect. It is a student who makes their own decision. Pit Corder (1991) argues "Error happens not because of a student lack of knowledge or experience but it happens because students failed to applicate the knowledge. Based on the terms stated above an errors occur because of less of competency meanwhile mistakes occur as the result of performance phenomena. It means errors can be analyzed and understand before we take an action but errors can't be corrected. Meanwhile, mistakes can be corrected because the students have already learned the knowledge.Erroranalysis distinguish between errors and mistake. Errors happen systematically while mistakes are not systematically.Errorareclassify into fourbasic type, they are emissive, additive, substitutive or related to word order.

According to Corder in (Ellis 1994)mistake is a part from error analysis. The error analysis should be a part of the errors that students made.Students may sometimes make errors and sometimes make mistakes. This can be a problem where students have partial knowledge of certain forms: Students' knowledge of the target language may not be complete; students may not learn all the contexts in which language rules can be used. Thus, students may make mistakes when trying to use what students perceive to be the correct form when in a particular context. Ellis gave an example of how a student can make mistakes because of partial knowledge. The following are examples that often occur (Feltsen, 2009): a. 'My brother is smarter than me'. b. 'My three brother are smarter than me.' The usage is correct in sentence a but in sentence b, error happens because of partial learning misleads students. In a lot of cases, we sometimes could distinguish between errors and mistakes. From those two sentences above, errors and mistakes almost same.By doing an analysis the sentences, errors could be seen as the result of students failed to understand about the rule of the target language, in another words, students still lack of competency or knowledge of the target language or it can be said that students' knowledge of the target language is limited.An error occurs when the students knowledge do not enough to understand the target language; so that students need to have more practice to acquire the knowledge of the target language. This means that students have already learned the language, but they need more time to learn. Some English teachers are unable to determine what is wrong and what is error. The English teacher considers the mistakes and errors that students make in the classroom while learning English as something wrong. The teacher should know if students make mistakes in the form of badwritting and spelling. When English teachers understand the te when then rms mistakes and errors, we might find the way how to solve those problems. Mistakes and errors are things that require a different method to 
solve.Fauziati (2009: 139) argued thatthe mistakes happen because of performance factors such as limitated memory, exhaustion and emotional tension.

Determining elements in the sample of language learners that deviate from the target language is the first step in analyzing errors and errors. For this aim, distinction should be made between error and mistake. According to James (as cited in Tiensawangchai, 2014) errors cannot be self-corrected until further relevant (to that error) input (implicit or explicit) has been provided and converted into intake by the learner. In other words, errors require further relevant learning to take place before they can be self-corrected. This means that students should be given certain forms of input, which may include a reading practice, writing practice, or a grammar lesson.

There are two sources of errors that are the focus of this research, Brown (as cited in Seitova, 2016) stated that interlingual errors and intralingual errors are two primary sources of errors. He also said that interlingual errors are those errors which are traceable to first language interference. These are attributable to negative interlingual transfer. Interference, language transfer, and cross-linguistic interference are also known as interlingual errors. Chelli (2013) stated that interlingual errors are the impact of language transform, which is caused by the learners' first language. When the students use their L1 linguistic knowledge to help them translate the target language, it could result in the errors that call interlingual errors (Richard 1974). According to Corder (1974) interlingual errors are errors attributed to the native language. These kinds of errors occur when the learners' habits (patterns, systems, or rules) interfere or prevent them from acquiring the patterns and rules of the target languageAlKhresheh (2010) argues that translation translation process has the potential to causeinterlingual errors. Transfer errors occur due to interference from the mother tongue. A student who does not yet know the rules of the target language will use the same rules as he obtained in the original language.

1. Interference from the first language that occurs when students try to find the structure of the target language using the transferant model of the mother tongue.

2. The occurrence of a literal translation process in which students tend to use words to translate expressions or sentences in the first language into the target language

According to Abusaeedi, dkk (2014) Intralingual errors refer to the difficulty of the target language learning, it occurs when the learners have difficulties in using the target language. Intralingual errors include: overgeneralization, simplification, communication- based, and induced error (Keshavarz, 2003). Errors made by students are not solely caused by disturbances in the student's language.Students' lack of understanding in learning the structure of the target language enable students to make mistakes in writing the target language well. Richard ( 1974) 
describes, the intralingual interference are items the target language made by learners, that express generalization particular description of the target language. Brown ( 1980 ) states a predominance of interlingual transfer defined the early stages of language learning, when the student has started to get whole parts of new system,the more transfer generalization of target language implemented.Richards ( as cited in Khansir, 2012) categorizes the intralingual errors into four categories; including overgeneralization, Ignore of rule restriction, Incomplete application of the rule, and false concepts hypothesized or semantic errors.

1. Overgeneralization, occurs where students write wrong structures that result from their experience of other structures of the target language; an extra extra "s" to the plural and there's not even an extra extra "s" to the singular.

2. Ignorance of the boundary rules, which occurs due to the failure of students to maintain existing boundaries or structures. Students tend to ignore the structure of the target language, they prefer the structure of the first language. This occurs when students fail to understand the boundaries of the target language structure that has been determined. Some rule errors can be justified in terms of analogy and may result from learning the role of rules.

3. The application of incomplete rules arising when the learners fail to develop a certain structure fully required producing acceptable sentences. This kinds of errors occur when students do not understand the more complex types of target language structures because they can communicate by applying simpler target language rules.For example: how you say it in English? In this case, the student uses statement form in the question. He omits the auxiliary $d o$ where it is necessarily placed before the subject.

4. False concepts hypothesized, deriving from faulty comprehension of distinctions in the target language. Learners' faulty understanding of distinctions of target language items leads to false concept hypothesized.

Several previous studies have shown that students make mistakes because of the first language factor. Besides, errors also occur because students do not understand or know aspects of the target language. This causes students to make mistakes not only in grammar but also in the use of aspects of the target language, such as the use of prepositions. A research conducted by Chelli (2013) shows that many students make make both errors and mistakes in the use of prepositions and article. The results showed that $79.15 \%$ of cases occurred due to the use of prepositions. While the use of articles causes students to make mistakes of $72.85 \%$. This is due to the negative transfer of their first language. While $20.85 \%$ of the total cases, errors occurred in the use of prepositions and $27.15 \%$ in the use of articles due to excessive generalizations and wrong concepts that were hypothesized by students. Another study by Solano (2014) revealed that the first language (Spanish) affects EFL students when they write English sentences. This is 
often due to the transfer of linguistics from the first language to the target language. $\mathrm{He}$ classified the common mistakes he found in his research to be misuse of verbs, omission of personal and object pronouns, prepositional columns, excessive use of articles, and inappropriate word order.From these researches, it can be concluded that the aspects of the students 'first language greatly affect the students' ability to write English sentences. Another factor that affects students' abilities is the lack of knowledge of students about the target language.Indonesianstudentslearn English as a compulsory subject at almost all levels of education. However, there are still many students who have difficulty writing, especially those related to grammar.

This study focuses on students' errors that occur when asked to write simple present tense to non-English language education students at a private university in the border area of West Kalimantan. The use of multiple verbs in simple sentences occurs most often. On the other hand, students still confused to distinguish between the use of auxiliary verbs and the main verb in one sentence. In addition, the use of extra "s / es' to certain verbs where the subject is a single sentence still be the problem for the students.Based on these problems, the researchers conducted this research to get an overview of the causes of students making mistakes in writing simple present tense sentences. This research aims to describe the factors that affect students' ability in writing simple present tense sentences seen from two types of sources of error, namely interlingual and intralingual. Through this research, the researchers investigate the kinds of errors made by the students in writing simple present tense sentences and they would conclude them as an error or mistakes. As a result, the researchers would provide recommendations or solutions to correct student errors in writing simple present tense sentences.

\section{METHOD}

In this study, researchers used a qualitative research design. According to Berg (2001), qualitative researchers correctly seek answers to questions by examining the various social and individual settings that inhabit these settings. Qualitative researchers, then, are most interested in how humans organize themselves and their arrangements and how the inhabitants of these arrangements understand their environment through symbols, rituals, social structures, social roles, and so on. Qualitative procedures provide a means of accessing unrecognizable facts about the real person being observed and talking to or the person represented by their imprint (such as letters, photos, newspaper accounts, diaries, etc.). As a result, qualitative techniques allow researchers to share the understandings and perceptions of others. This technique also allows researchers to explore how people structure and give meaning to their daily lives. In analyzing the data, the researchers used this qualitative research design to describe the various forms of errors or mistakes made by Non-English students study program when writing simple 
present tense. Besides, this method is also used to provide an overview of the factors that influence the students to make mistakes or errors in writing the simple present tense. At the end of the analysis, the researchers would distinguish that students made errors or mistakes when writing the tense.

To describe the various forms of errors or mistakes made by non-English study program students when writing the simple present tense, researchers used a qualitative technique. The qualitative data in this study were in the form of students' worksheets containing ten simple sentences of present tense written by non-English study program students. The data was taken directly from the students, where the students were asked to translate ten simple sentences in the form of simple present tense. Determination of the subject and object of research using purposive sampling; the number of samples is adjusted to the needs of the study. Samples were taken from eight study programs in a private university in the border area, west Borneo.

The researchers analyzed the data through several stages. The first step, the researchers read several theories related to the research. At this stage the researchers read several books and articles to strengthen the researchers' ideas and knowledge. The next step is to make field observations; At this stage the researchers analyzed the research needs and the research location. Furthermore, the researchers conducted research preparation. At this stage the researchers conduct discussions to design research objectives, scope, study of theories, methods, and time. The next step is data collection; Researchers used purposive sampling to collect data. In this case, the researchers asked the students to translate ten sentences into the simple present tense, based on the students understanding and experience from the previous level of education.Then the data was selected based on the research needs.The next step is data analysis; this step is divided into several stages. In the first stage, the researchers coded each item based on the mistakes or errors made by the students. There were ten codes referring to the students' mistakes.The researchers conducted a decoding process to find out the meaning of the code. Then the researchers categorized the students' errors or mistakes based on the types of errors according to the code that had been made. Furthermore, the researchers presented the data in the form of tables and diagrams to facilitate the description. At this stage, the researchers also performed data reduction to meet the research needs. The final step, the researchers describes the data and concluded the research results based on the findings in this study.

\section{FINDING AND DISCUSSION}

The object of this research is a student worksheet document that is obtained directly from non-English study program students. To obtain this document, the researchers asked students to translate ten sentences from Indonesian into English in the simple present tense form. The first step the researchers took in analyzing the data was coding. In this stage the researchers made 
some codes and the meanings of the codes. The researchers made the codes to define the the mistakes or errors made by the students based on the observation before this stage.

Table 1.Coding and Meaning

\begin{tabular}{|c|l|l|}
\hline No & \multicolumn{1}{|c|}{ Coding } & \\
\hline 1 & ESM & Extra 'S/ES' matter \\
\hline 2 & VingM & V+Ing Matter \\
\hline 3 & TM & TOBE matter \\
\hline 4 & DVM & Double verbs matter \\
\hline 5 & NFM & Negatif form matter \\
\hline 6 & PPM & Personal pronoun matter \\
\hline 7 & STVM & Second, third verbs matter \\
\hline 8 & WOM & Word order matter \\
\hline 9 & PRM & Preposition matter \\
\hline 10 & OM & Other matter \\
\hline
\end{tabular}

Those codes are used by researchers to limit the scope of the problems to be analyzed or described in this study. Researchers made observations on student worksheets using the codes. Furthermore, the researchers classified the types of errors made by students using the codes.

The data analysis in this study was taken from 120 Non-English Study program students at a private university in the border area of West Kalimantan. In this case the researchers applied purposive sampling to determine the subject of the research. Based on the number of sampling of the research, the researchers analyzed 120 worksheets of the students translation task. The researchers found 395 cases, in which one student contributed more than one cases.

\section{Chart 1. Case Percentage}

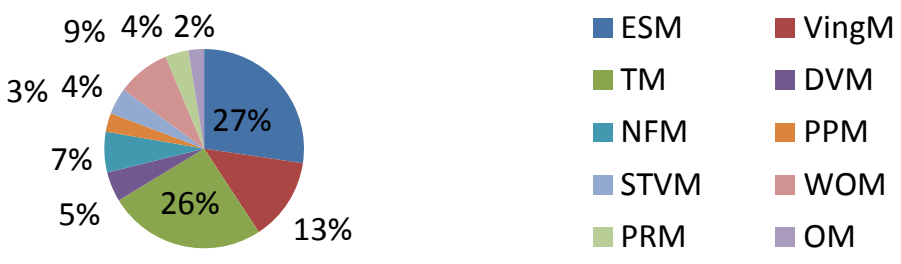

The results showed that the most common problem was the addition of extra 's/es' to a verb the code is 'ESM'. One of the characteristics of the simple present tense is the addition of 's/es' to a verb when the subject of the sentence is single. The rule of adding extra 's/es' to a verb in simple present tense influenced the students to make errors as many as 108 cases or $27.3 \%$ of the total cases encountered in this study. The next most frequent case is the misuse of 'To Be', apart from misusing 'tobe' the students failed to understand the type of sentence that needed to use 'tobe' or not. There are differences in the use of tobe in simple present tense, especially nominal sentences, made students confused to determine the appropriate tobe for a particular subject. Misuse 'tobe' form the code is 'TM' contributed 101 cases or 26\%. The top three most common cases found in this research is Ving matter (VingM) which contributed 53 cases or $13 \%$ of total cases. For students the use of 'Ving' is a common thing, this is because 
students often practically use the Ving verb spontaneously. However they also use ving inappropriately. This becomes a problem when students write simple present tense. Data in chart 1 showed that students' understanding about personal pronounalsoinflunced the student to contribute in making errrors. The most problems in using personal pronouns, the students could not distinguish the form of personal pronoun for subject or object. Personal pronoun matter (PPM) contributed 12 cases. 9\% of total cases showed that the students failed to construct the words order in english sentences. The researchers also found $7 \%$ cases of errors where the students could not write nagatif sentence appropriately. In forming negatif sentences the students could not distiguish do/does forms. From the data analysis, the researchers confirmed that students also failed to recognize main verb and helping verb. The put put the two verbs in one sentence. In this study, the researchers classified the errors as double verb matter, in which the students added 'to be'form to verbal sentence.Double verb matter contributed 19 cases or $5 \%$. The analysis also showed that $8 \%$ of the total errors were caused by students' difficulties in understanding the types of verbs and the use of prepositions. The code used by researchers for misuse of verbs is STVM and the PRM code is used for misuse of prepositions.

Based on research data,researchers focused on the three types of errors that were most commonly found in this study. First, the researcher found that the students failed to understand the addition of extra 's / es' to the main verb. This is influenced by the difference in the treatment of words in the simple present tense, where the sentence with the singular subject of the word that follows it gets an extra 's / es' while in plural sentences the verb that follows does not change. In this study, the differences in the treatment of these verbs made students make many mistakes in writing simple present tense sentences. The second most common case in this research is the misuse of the form "to be" or the auxiliary verb. This error is mostly found when students translate non-verbal sentences. The students could not use correct form of 'to be' in accordance with the subject of the sentence, students also fail to understand that a sentence will not be complete if it does not have a verb in it. One of the most important elements for nominal sentences is the addition of 'to be'. In additional, the use of two forms of 'to be' in one sentence also occurs in this case.Apart from the two cases above, the focus of the researchers in this study is the types of errors that arise as a result of students using the verb+ing or Ving when writing simple present tense. in this case the students fail to understand the difference in the meaning or function of the sentence using Ving and the first verb. from this case it can be understood that many students consider that the use of Ving does not have any impact on the sentences they write. besides that, students also failed to understand the correct writing of the Ving sentence. Based on the findings in the student's research, they mistakenly used the verb + ing, where they only used it without adding the 'be' form before the word. This causes the 
sentence to not be grouped into simple tense or progressive tense. The main thing that happens here is that students fail to understand the verb tenses used in the simple present tense.Apart from the three main cases above, the students' ability in composing English sentences and making negative sentences is also still inadequate. Students fail to correct the structure or composition of English sentences. in this case, students translate words, so that the sentence structure is also very similar to Indonesian sentences. Some sentences in this study have the same structure as the sentences in the target language, but when students translate different sentence structures, word composition errors are not avoided. Meanwhile, in forming negative sentences, students fail to understand the difference between nominal sentences and verbal sentences. The thing most often encountered in this study was that students only added notes for negative sentences. other things also fail to apply the use of the do / does correctly. in this study these two types of errors accounted for $16 \%$ of the total cases.In analyzing the data, the researcher also found other cases that were not shown as detailed as in this study. The total other cases is $10 \%$. The $10 \%$ of cases occur because students do not understand the use of articles, word choices and even mistakes in writing words. The reserachers did not display the data because it is not part or the main characteristic of the simple present tense.The researchers considered the other cases as a part of all tenses in English.In addition, the researchers limited this study where the researchers only investigated errors in writing simple present tense sentences.

\section{CONCLUSION}

To sum up, this research was conducted to describe the various forms of errors and mistakes found in the translation of simple present tense sentences by non-English study program students at a private university in border area, west Borneo. Researchers found a total of 395 cases from 120 student worksheets. Broadly speaking, these cases are classified into ten types of errors. The findings showed that all cases described in this study were categorized as errors. From the data analysis, the researchers found that the students failed to carry out their knowledge of the simple present tense. In this case the students did not make mistakes since they have learned the simple present tense in SMP and SMA level.Errors found in this researcharised because of mother tongue interference, literal translation, overgeneralization, ignorance of rule restriction, incomplete application of and false concepts hypothesized.The errors found in this study were due to the difficulty of the target language. In this case, English has a different verb according to the time it happends, while in Indonesia the time does not affect the verbs. The most common errors found in this study, such as the rule of adding extra 's / es', the rule of using 'Tobe' and the errors that arise due to Ving replenishment of the first verb in the present tense can be minimized with regular writing practice. The researchers recommend 
that teachers pay more attention to every aspect of the composition of the simple present sentences, such as the subject and the verbs that follow. On the other hand, in giving writing exercises, especially present tense sentences, avoid giving the task of translating words to words.Provide more explanation about the role of 'tobe' in a sentence, emphasize the explanation of verbal and non-verbal sentences where 'tobe' is only used in non-verbal sentences in the simple present tense.In explaining the simple present tense, it should be explained together with the present progressive so that students can compare the differences between the two verbs used in each tense. So that the error of using Ving in the simple present tense can be avoided.

\section{REFERENCES}

Al- Khresheh, M.H. (2010). Interlingual interference in english language word order structure of jordanianefl learners. Proceedings of the European Journal of Social Sciences Volume 16, Number 1.

Berg, Bruce.L.(2001). Qualitative research method for the social sciences: Boston. Pearson Education Company.

Brown , H.(2007). Principles of language learning and teaching. New Jersey: Prentice Hall Inc.

Corder, S. P. (1991): Error Analysis and Interlanguage. Oxford: Oxford University Press.

Chelli, Saliha. (2013). Interlingual and intralingua errors in the use of preposition and articles.As retrieved from http://dspace.univbiskra.dz:8080/jspui/bitstream/123456789/3571/1/Interlingual\%20or\%20Intralin gal\%20Errors\%20in\%20the\%20Use\%20of\%20 Preposition.pdf

Ellis, R. (1994). The study of Second Language Acquisition: Oxford University Press.

Fauziati, Endang. (2009). Readings on applied linguistics: a handbook for language teacher and teacher researcher. Surakarta: Era PustakaUtama

Feltsen, P. (2009). Language acquisition and the errors we make. (Mid Sweden University), 26.

Keshavarz, M. H. (2003). Error analysis and contrastive analysis in translation and learner translation. Oxford: Oxford University Press.

Khansir, A.A. (2012). Error analysis and second language acquisition.Theory and practice in language studies. 2 (5) 1027-1032

Leacock, C., Chodorow, M., Gamon, M., \& Tetreault, J. (2010). Automated grammatical error detection for language learners: University of Toronto.

Richard, J, C. (2014). Error analysis: perspective on second language acquisition. London: Longman Group Ltd.

Seitova, Meruyert. (2016). Error analysis of written production: the case of 6th grade students of kazakhstani school. Procedia-Social behaviorialscience.232(287293)

Solano, Paola Alexandra Cabrera. 2014. Spanish interference in efl writing skills: a case of ecuadorian senior high schools. Canadian Center of Science and Education.Vol. 7 No. 7.

Tiensawangchai, Tanom. (2014). Types of grammar errors found in thaiefl students' bussiness writing. International Journal of art \& sciences. 07(02) 545-555 